\title{
СИНТЕЗ И КОЛЛОИДНО-ХИМИЧЕСКИЕ СВОИСТВА ПОВЕРХНОСТНО-АКТИВНЫХ ВЕЩЕСТВ ТИПА НАТРИЕВЫХ СОЛЕЙ N-ДИАЛКИЛАМИНО-N-ЭТАНСУЛЬФОКИСЛОТ
}

\author{
(Представил Ю. Лилле)
}

Анионноориентированные амфолитные поверхностно-активные вещества (ПАВ) типа натриевых солей $\mathrm{N}$-алкиламино-N-этансульфокислот с общей формулой

$$
\mathrm{RNHCH}_{2} \mathrm{CH}_{2} \mathrm{SO}_{3} \mathrm{Na}
$$

находят применение в бытовой химии $[1,2]$, при изготовлении фотоматериалов $\left[{ }^{3}\right]$, в качестве ингибиторов коррозии $\left[{ }^{4}\right]$ и т. д. Их синтез чаще всего осуществляют путем конденсации длинноцепочечных галоидных алкилов с натриевыми солями 2-аминоэтансульфокислот [ $\left.{ }^{5-7}\right]$. В результате реакции образуются побочные продукты диалкилирования натриевые соли $\mathrm{N}$-диалкиламино-N-этансульфокислот с общей формулой

$$
\text { (R) }{ }_{2} \mathrm{NCH}_{2} \mathrm{CH}_{2} \mathrm{SO}_{3} \mathrm{Na} \text {. }
$$

Удаление последних из реакционной смеси - процесс весьма трудоемкий. В литературе имеются ссылки на то, что некоторые N-диалкилпроизводные обладают поверхностно-активными свойствами, если R' в формуле RR' $\mathrm{NCH}_{2} \mathrm{CH}_{2} \mathrm{SO}_{3} \mathrm{Na}$ является коротким алкильным радикалом [ $\left.{ }^{8}\right]$. Однако отсутствуют данные о коллоидно-химических свойствах веществ типа II, когда обе алкильные цепи имеют равную длину - от $\mathrm{C}_{8}$ до $\mathrm{C}_{16}$.

Таблица 1

Выход и элементный состав натриевых солей

\begin{tabular}{|c|c|c|c|c|c|c|c|}
\hline \multirow[b]{2}{*}{ Натриевая соль } & \multirow{2}{*}{$\begin{array}{c}\text { Выход, } \\
\%\end{array}$} & \multicolumn{2}{|c|}{$\mathrm{N}$} & \multicolumn{2}{|c|}{ C } & \multicolumn{2}{|c|}{$\mathrm{H}$} \\
\hline & & reop. & эксп. & теop. & эКсп. & теop. & эксп. \\
\hline
\end{tabular}
$\mathrm{N}$-диалкиламино-N-этансульфокислот, \%

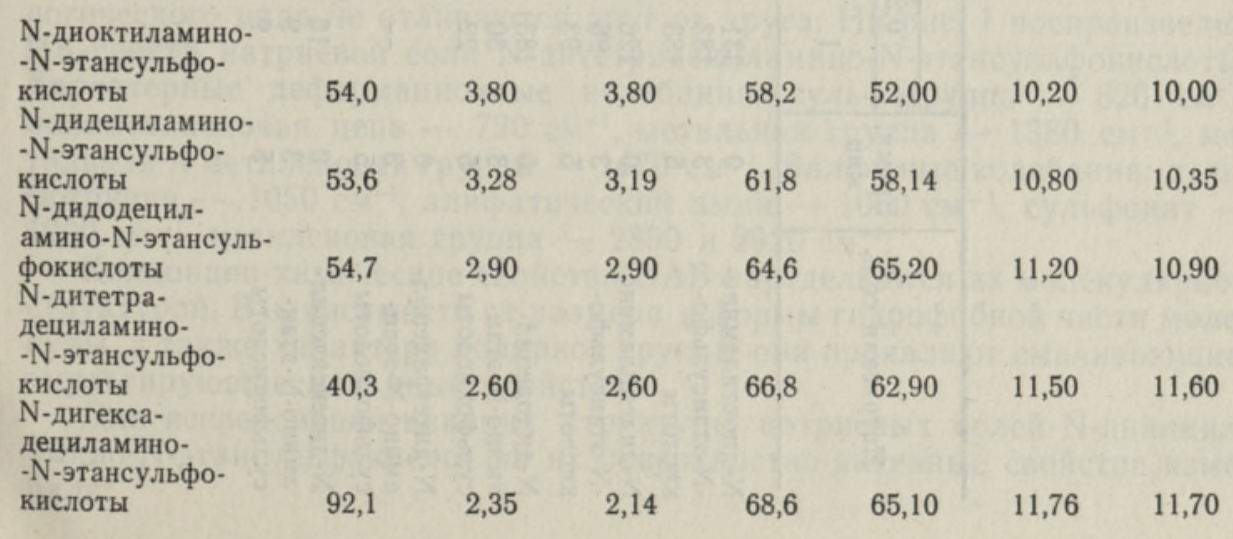




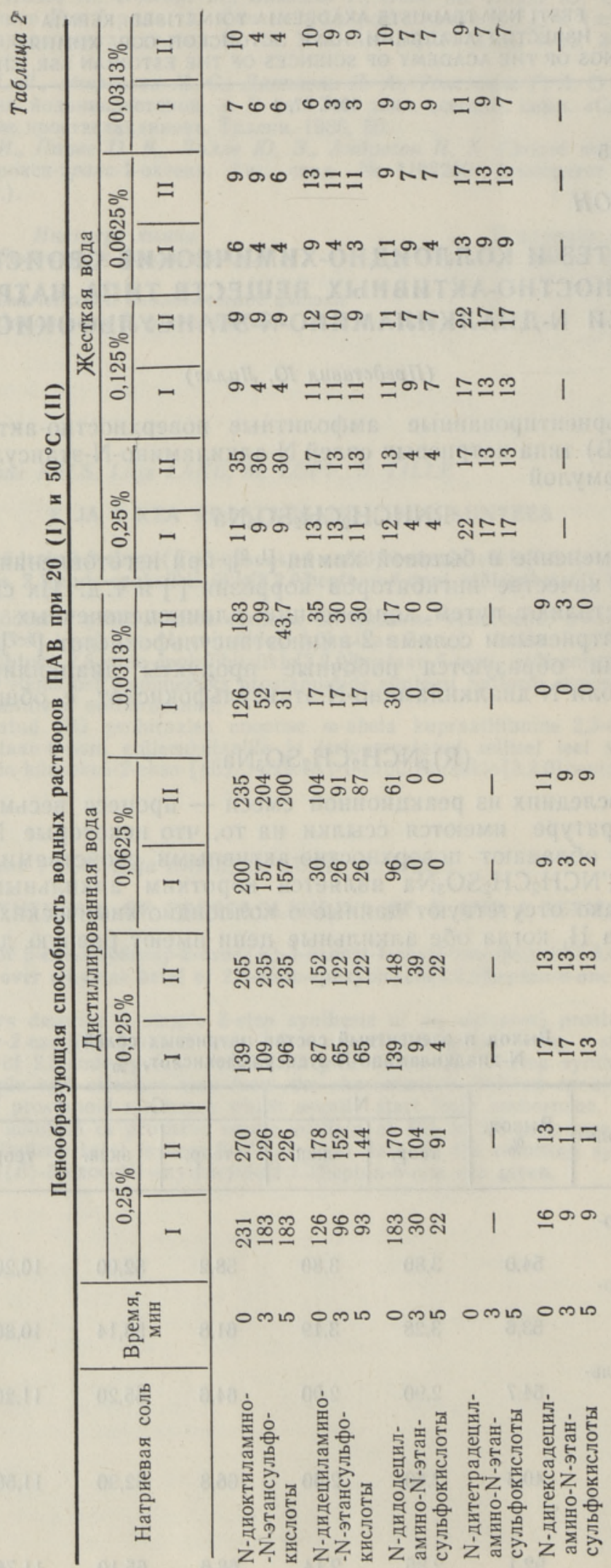




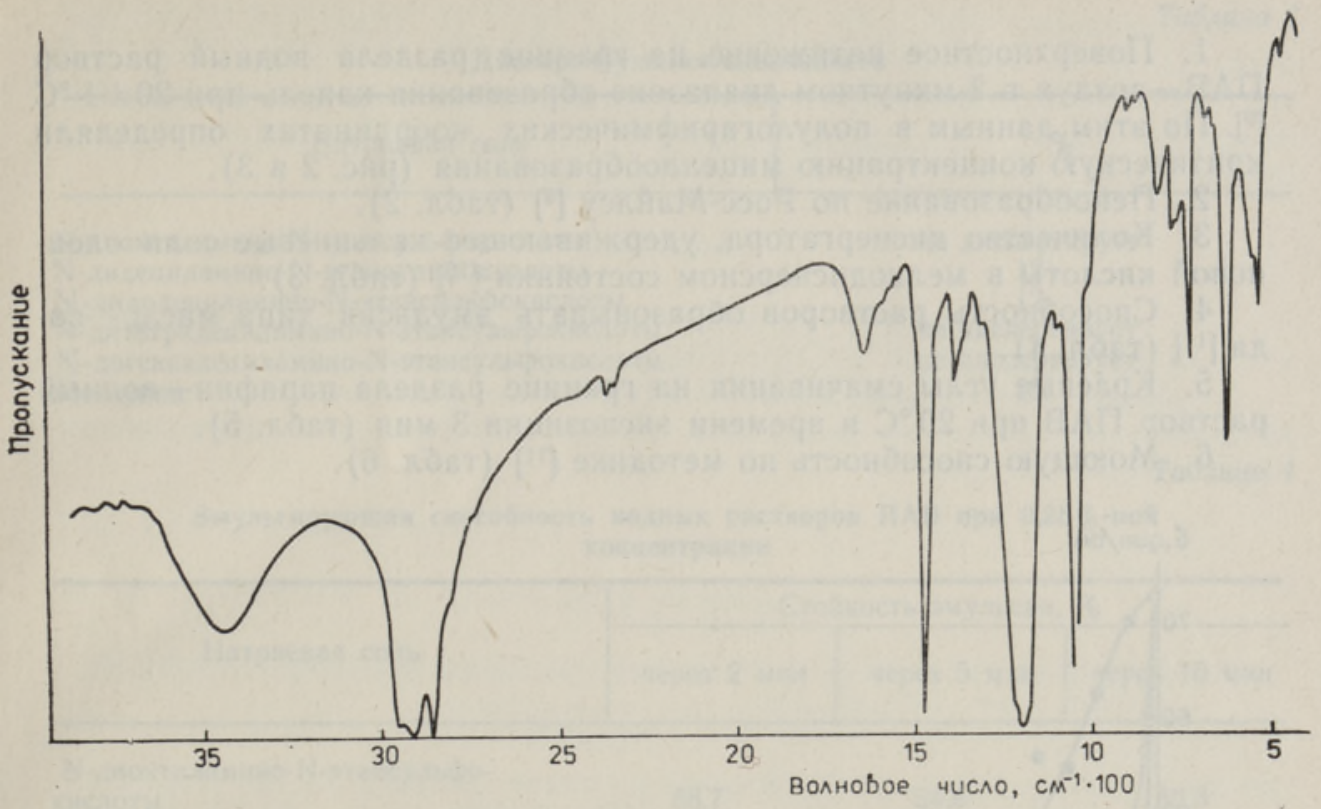

Рис. 1. ИК-спектр натриевой соли N-дитетрадециламино-N-этансульфокислоты.

Для установления влияния примесей типа II на поверхностно-активные свойства ПАВ, приготовленных на базе натриевых солей $\mathrm{N}$-алкиламино-N-этансульфокислот, нами был синтезирован гомологический ряд натриевых солей $\mathrm{N}$-диалкиламино-N-этансульфокислот. Данные о зависимости между структурой и свойствами веществ типа II дают ответ на вопрос, нужно ли их отделять от веществ типа I при изготовлении технических ПАВ.

Для получения продуктов типа II алкилбромиды кипятили с натриевой солью 2-аминоэтансульфокислоты в течение 18 ч при мольном соотношении реагирующих компонентов $1: 1$. Реакцию проводили в $74 \%$-ном этаноле. После охлаждения реакционную смесь разбавляли 750 мл $47 \%$-ного этанола. Из реакционной смеси N-диалкиламино-N-этансульфокислоту выделяли бензолом. Затем растворитель выпаривали, и полученный продукт растворяли в этаноле. $10 \%$-ным раствором $\mathrm{NaOH}$ доводили $\mathrm{pH}$ до 9. Смесь высушивали, остаток перекристаллизовывали из этилового спирта. Выход и элементный состав натриевых солей N-диалкиламино-N-этансульфокислот приведены в табл. 1 .

Полученные препараты идентифицировали по ИК-спектрам, снятым на приборе «Specord IR 75». Спектры отдельных представителей гомологического ряда не отличаются друг от друга. На рис. 1 воспроизведен ИК-спектр натриевой соли $\mathrm{N}$-дитетрадециламино-N-этансульфокислоты. Характерные деформационные колебания: сульфогруппа $-620 \mathrm{~cm}^{-1}$, полиметиленовая цепь - $720 \mathrm{~cm}^{-1}$, метильная группа $-1380 \mathrm{~cm}^{-1}$, метильная и метиленовая группы $-1470 \mathrm{~cm}^{-1}$. Валентные колебания: сульфогруппа - $1050 \mathrm{~cm}^{-1}$, алифатический амин - $1060 \mathrm{~cm}^{-1}$, сульфонат $1200 \mathrm{~cm}^{-1}$, метиленовая группа -2850 и $2920 \mathrm{~cm}^{-1}$.

Коллоидно-химические свойства ПАВ определяются их молекулярной структурой. В зависимости от размера и формы гидрофобной части молекулы, а также характера полярной группы они проявляют смачивающие, эмульгирующие или иные свойства.

Для исследования влияния структуры натриевых солей $\mathrm{N}$-диалкиламино-N-этансульфокислот на их поверхностно-активные свойства измеряли: 
1. Поверхностное натяжение на границе раздела водный раствор ПАВ-воздух в 2-минутном диапазоне образования капель при $20 \pm 1^{\circ} \mathrm{C}$ [9]. По этим данным в полулогарифмических координатах определяли критическую концентрацию мицеллообразования (рис. 2 и 3).

2. Пенообразование по Росс-Майлсу [ $\left.{ }^{9}\right]$ (табл. 2) .

3. Количество диспергатора, удерживающее кальциевые соли олеиновой кислоты в мелкодисперсном состоянии $\left[{ }^{10}\right]$ (табл. 3).

4. Способность растворов образовывать эмульсии типа масло-вода $\left[{ }^{11}\right]$ (табл. 4).

5. Краевые углы смачивания на границе раздела парафин-водный раствор ПАВ при $20^{\circ} \mathrm{C}$ и времени экспозиции 3 мин (таб̆л. 5).

6. Моющую способность по методике [11] (табл. 6).

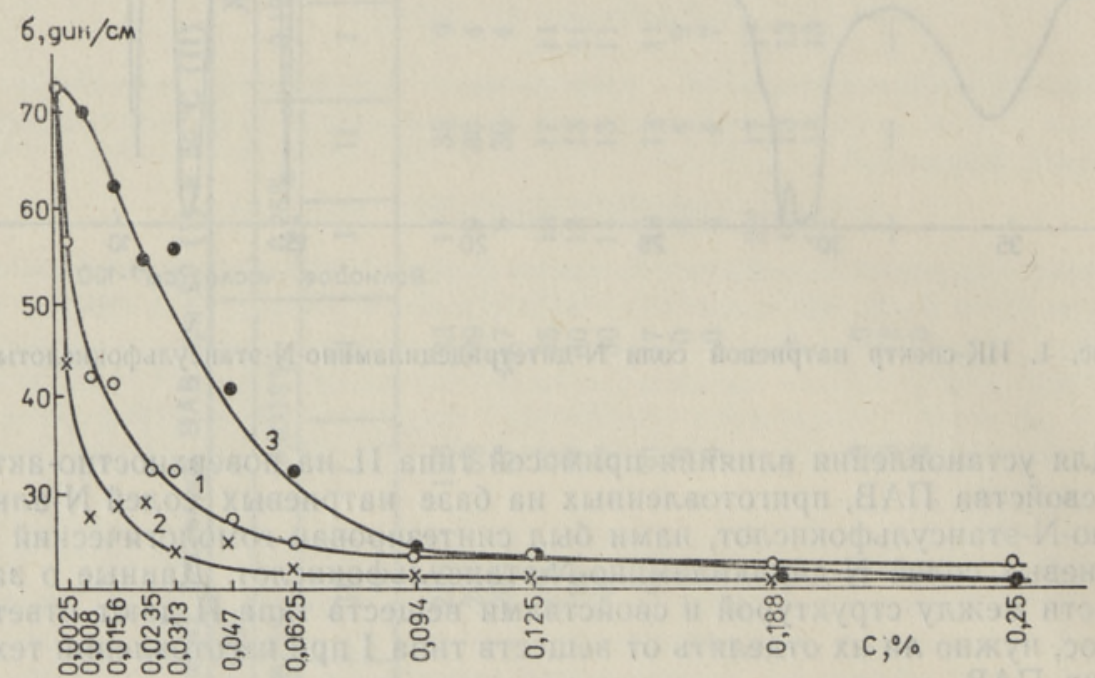

Рис. 2. Изотермы поверхностного натяжения $(\sigma)$ водных растворов натриевых солей $\mathrm{N}$-диоктиламино- (1), N-дидециламино- (2) и $\mathrm{N}$-дидодециламино- $\mathrm{N}$-этансульфокислот (3).

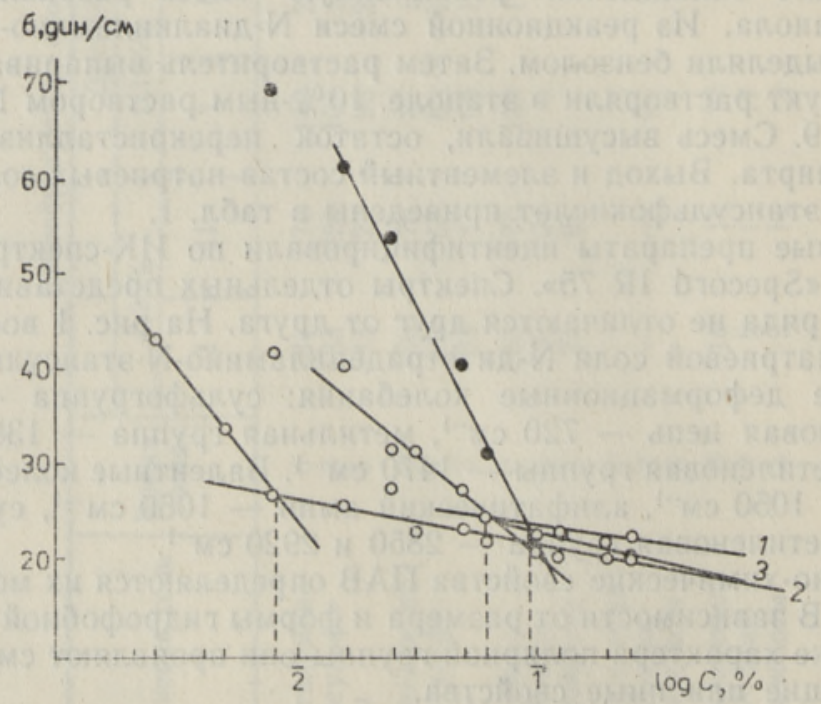

Рис. 3. Зависимость поверхностного натяжения (б) водных растворов натриевых солей $\mathrm{N}$-диоктиламино- $(1, \mathrm{KKM}=0,063 \%), \mathrm{N}$-дидециламино- $(2, \mathrm{KKM}=0,008 \%)$ и $N$-дидодециламино-N-этансульфокислот $(3, \mathrm{KKM}=0,093 \%)$ от $\log C$. 
Диспергирующая способность

\begin{tabular}{l|l}
\hline Натриевая соль & $\%$ \\
\hline
\end{tabular}

$\mathrm{N}$-диоктиламино-N-этансульфокислоты $\mathrm{N}$-дидециламино-N-этансульфокислоты $\mathrm{N}$-дидодециламино-N-этансульфокислоты $\mathrm{N}$-дитетрадециламино-N-этансульфокислоты $\mathrm{N}$-дигексадециламино-N-этансульфокислоты Метаупон не диспергирует

12

12

не диспергирует

не диспергирует

16

Таблица 4

Эмульгирующая снособность водных растворов ПАВ при 0,25\%-ной концентрации

Натриевая соль

Стойкость эмульсии, \%

\begin{tabular}{l|l|l} 
через 2 мин & через 5 мин & через 10 мин
\end{tabular}

$\mathrm{N}$-диоктиламино-N-этансульфокислоты

$\mathrm{N}$-дидециламино-N-этансульфокислоты

$\mathrm{N}$-дидодециламино-N-этансульфокислоты

$\mathrm{N}$-дитетрадециламино-N-этансульфокислоты

$\mathrm{N}$-дигексадециламино-N-этансульфокислоты

ОП-7

66,7

70,2

50,0

39,4

28,6

67,7
54,6

67,6

37,5

33,3

23,1

66,7
33,3

63,0

23,1

28,6

таблица 5

Краевой угол смачивания водных растворов ПАВ

\begin{tabular}{l|l|l|l|l|l}
\hline \multirow{2}{*}{ Натриевая соль } & \multicolumn{5}{|c}{ Концентрация, $\times 10^{-3} \mathrm{M}$} \\
\cline { 2 - 4 } & 4 & 2 & 1 & 0,5 & 0,25 \\
\hline
\end{tabular}

$\mathrm{N}$-диоктиламино-N-этансульфокислоты $\mathrm{N}$-дидециламино-N-этансульфокислоты

$\begin{array}{ll}- & 25 \\ 23 & 19\end{array}$

14

20 30 
Исследования показали, что вещества типа II являются полноценными ПАВ, но практическому использованию высших гомологов препятствует их неудовлетворительная растворимость в холодной воде. По эмульгирующей способности натриевые соли $\mathrm{N}$-диалкиламино-N-этансульфокислот не уступают обычно используемому ОП-7.

\section{Выводы}

1. Разработан способ получения поверхностно-активных веществ типа натриевых солей $\mathrm{N}$-диалкиламино-N-этансульфокислот.

2. По коллоидно-химическим свойствам эти ПАВ не отличаются от веществ типа I, поэтому разделять их при изготовлении технических ПАВ нецелесообразно.

\section{Л ИТЕ Р А Т У Р А}

1. Cahn, A., Kaniecki, T. J. N-(2-Hydroxyalkyl)-N-methyltaurines. Belg. 618,901 (1962). - Chem. Abstr., 1964, 60, 1596.

2. Johnson, G. A. Detergent composition. Brit. 1,336,556 (1973). - Chem. Abstr., 1974, $80,147177$.

3. Fikentscher, H., Willersinn, H., Penning, E., Distler, H. Stable polymer dispersions. Ger 1,129,284 (1962). - Chem. Abstr., 1962, 57, 6130.

4. Marumo, H., Maruyama, K. Rust inhibitors for lubricating oils. Jap. 68 19,223. Chem. Abstr., 1969, 71, 41034.

5. Томсон $P$., Файнгольдे С. Синтез алкиламиноэтилсульфонатов. - Изв. АН ЭССР. Хим. Геол., 1976, 25, № 4, 297-301.

6. Файнгольд C., Томсон $P$., Маспанов $H$. Синтез и коллоидно-химические свойства $H$-алкиламиноэтилсульфатов и $\boldsymbol{H}$-алкиламиноэтилсульфонатов. - Маслоб.-жир. пром-сть, 1976, № 10, 22-26.

7. Файнгольд С., Томсон Р., Ройз Д., Лаан В. Способ получения алкиламиноэтилсульфоната. - Открытия, изобретения, 1980, № 33, авт. свид. СССР № 761459.

8. Matsubara, Y., Kasano, M., Tajima, K., Kawamoto, S. Surfactants containing terpenyl groups. V. Synthesis and their surface activity of sulfonated type amphoteric surfactants from alkylisobornylmaleate. - Yaukagaku, 1974, 23, N 4, 257-258; Chem. Abstr., 1975, 82, 88035.

9. Неволин Ф. В. Химия и технология синтетических моющих средств. М., 1971.

10. Cahill, J. A., Lincoln, R. M., Meyers, J. A. Aminosulfonic acid dishwashing detergent. Fr. 1,557,528 (1969). - Chem. Abstr., 1970, 72, 33553.

11. Руководство по методам исследования, технохимическому контролю и учету производства в масло-жировой промышленности, IV. Л., 1963.
Институт химии
Академии наук Эстонской ССР
Поступила в редакцию 26/V 1988

\section{Rutt TOMSON}

\section{N-DIALKUULAMINO-N-ETAANSULFOHAPPE NAATRIUMISOOLADE SUNTEES JA NENDE KOLLOIDKEEMILISED OMADUSED}

Artiklis on esitatud N-dialküülamino-N-etaansulfohappe naatriumisoola tüüpi pindaktiivsete ühendite süntees. On määratud sünteesitud homoloogilise rea ühendite kolloidkeemilised omadused, et välja selgitada nende kasutussuunad.

\section{Rutt TOMSON}

\section{SYNTHESIS OF SODIUM SALTS OF N-DIALKYLAMINO-N- ETHANESULFOACID AND THEIR COLLOIDAL-CHEMICAL PROPERTIES}

The author reports the synthesis of surfactants of sodium salts of N-dialkylamino-N. ethanesulfoacid. The colloidal-chemical properties of the homologous series of the com. pounds synthesized have been determined to elucidate their practical application. 